\title{
Antioxidant effect of 4-nerolidylcatechol and $\alpha$-tocopherol in erythrocyte ghost membranes and phospholipid bilayers
}

\author{
K.S. Fernandes ${ }^{1}$, A.H.M. Silva ${ }^{1}$, S.A. Mendanha ${ }^{1}$, K.R. Rezende ${ }^{2}$ and A. Alonso ${ }^{1}$ \\ ${ }^{1}$ Instituto de Física, Universidade Federal de Goiás, Goiânia, GO, Brasil \\ ${ }^{2}$ Laboratório de Biofarmácia e Farmacocinética de Substâncias Bioativas, Faculdade de Farmácia, \\ Universidade Federal de Goiás, Goiânia, GO, Brasil
}

\begin{abstract}
4-Nerolidylcatechol (4-NC) is found in Pothomorphe umbellata root extracts and is reported to have a topical protective effect against UVB radiation-induced skin damage, toxicity in melanoma cell lines, and antimalarial activity. We report a comparative study of the antioxidant activity of 4-NC and $\alpha$-tocopherol against lipid peroxidation initiated by two free radical-generating systems: 2,2'-azobis(2-aminopropane) hydrochloride (AAPH) and $\mathrm{FeSO}_{4} / \mathrm{H}_{2} \mathrm{O}_{2}$, in red blood cell ghost membranes and in egg phosphatidylcholine (PC) vesicles. Lipid peroxidation was monitored by membrane fluidity changes assessed by electron paramagnetic resonance spectroscopy of a spin-labeled lipid and by the formation of thiobarbituric acid-reactive substances. When lipoperoxidation was initiated by the hydroxyl radical in erythrocyte ghost membranes, both 4-NC and $\alpha$-tocopherol acted in a very efficient manner. However, lower activities were observed when lipoperoxidation was initiated by the peroxyl radical; and, in this case, the protective effect of $\alpha$-tocopherol was lower than that of 4-NC. In egg PC vesicles, malondialdehyde formation indicated that 4-NC was effective against lipoperoxidation initiated by both AAPH and $\mathrm{FeSO}_{4} / \mathrm{H}_{2} \mathrm{O}_{2}$, whereas $\alpha$ tocopherol was less efficient in protecting against lipoperoxidation by $\mathrm{AAPH}$, and behaved as a pro-oxidant for $\mathrm{FeSO} \mathrm{O}_{4} / \mathrm{H}_{2} \mathrm{O}_{2}$. The DPPH (2,2-diphenyl-1-picrylhydrazyl) free-radical assay indicated that two free radicals were scavenged per 4-NC molecule, and one free radical was scavenged per $\alpha$-tocopherol molecule. These data provide new insights into the antioxidant capacity of 4-NC, which may have therapeutic applications for formulations designed to protect the skin from sunlight irradiation.
\end{abstract}

Key words: Electron paramagnetic resonance; 4-Nerolidylcatechol; Spin label; Lipid peroxidation; DPPH (2,2-diphenyl-1picrylhydrazyl)

\section{Introduction}

The compound 4-nerolidylcatechol (4-NC) can be isolated from the root of Pothomorphe umbellata L. Miq. (1), a native plant of the Brazilian Atlantic Forest that is more commonly known as "pariparoba". $P$. umbellata root extracts have demonstrated antioxidant activity against spontaneous brain lipid peroxidation in vitro, as evaluated by malondialdehyde (MDA) formation and chemiluminescence emission. Part of this protection has been attributed to 4-NC (2). As an antioxidant, $P$. umbellata root extracts and 4-NC have also demonstrated topical protective activities against UVB radiation-induced skin damage and prevented $\alpha$-tocopherol depletion in the skin of hairless mice following UVB exposure $(3,4)$. $P$. umbellata root extracts, and, to a lesser extent, 4-NC can inhibit activity of the metalloproteinases MMP-2 and MMP-9 (5), which are family members of a group of matrix-degrading enzymes, and whose synthesis is increased in response to UV irradiation. These metalloproteinases play important roles in morphogenesis, angiogenesis, arthritis, skin ulcer formation, tumor invasion, and metastasis $(6,7)$. Furthermore, it has been shown that $4-\mathrm{NC}$ is able to induce apoptosis in melanoma cell lines $(8,9)$ and that 4 $\mathrm{NC}$ derivatives have significant antimalarial and cytotoxic potential $(10,11)$.

Both vitamin E and 4-NC molecules are hydrophobic (Figure 1); thus, in its role as an antioxidant, 4-NC is likely to protect the cell membrane from lipid peroxidation. Lipid peroxidation is initiated by reactive oxygen species (ROS), such as hydroxyl radicals, ( $\left.{ }^{\circ} \mathrm{OH}\right)$, alkoxyl radicals (LO'), and the peroxyl radical (LOO'), which can abstract a 


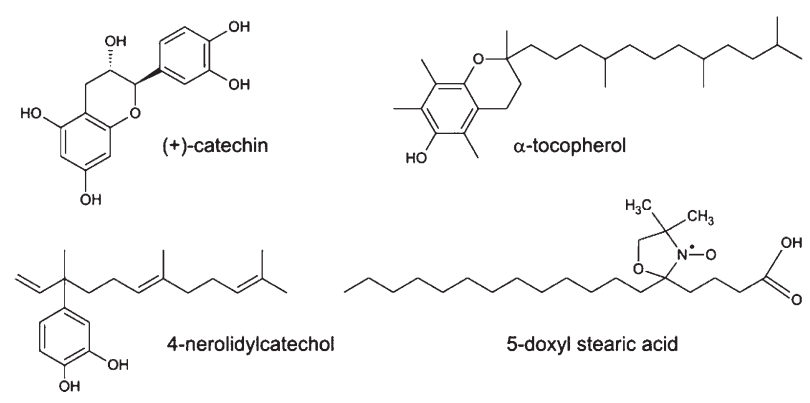

Figure 1. Structure of $(+)$-catechin, $\alpha$-tocopherol, 4-nerolidylcatechol (4-NC), and the spin label 5-doxyl stearic acid (5-DSA).

hydrogen atom from the methylene group of an unsaturated fatty acid, forming a carbon-centered radical that combines with oxygen to form a peroxyl radical that is able to abstract another hydrogen atom $(12,13)$. Peroxidation propagates until a chain-breaking antioxidant such as vitamin $\mathrm{E}$ is able to stop the chain reaction or until two free radicals annihilate each other to terminate the chain reaction by forming cyclic peroxide (LOOL) (12). Extensive lipid peroxidation in the cell causes a loss of membrane fluidity, a decrease in membrane potential, and electrolyte leakage $(12,14)$. Membrane stiffness associated with lipid peroxidation has been assessed by electron paramagnetic resonance (EPR) spectroscopy with spin labeling (14-17) and by the spectroscopy of fluorescent probes $(18,19)$, which has proved to be very reliable in detecting the occurrence of lipid peroxidation.

We used EPR spectroscopy to evaluate the protective effects of 4-NC against lipid peroxidation initiated by the free radical-generating systems 2,2'-azobis(2-aminopropane) hydrochloride (AAPH) or $\mathrm{FeSO}_{4} / \mathrm{H}_{2} \mathrm{O}_{2}$ in isolated erythrocyte membranes. For comparison, the effect of $\alpha$-tocopherol was evaluated in parallel. The antioxidant potentials of 4-NC and $\alpha$-tocopherol were also tested by analyzing MDA formation in egg phosphatidylcholine (PC) vesicles and erythrocyte ghost membranes using the same initiators of lipid peroxidation.

\section{Material and Methods}

\section{Chemicals}

$\alpha$-tocopherol, the 5-doxyl stearic acid (5-DSA) spin label, (+)-catechin (Figure 1), 2,2-diphenyl-1-picrylhydrazyl (DPPH), egg phosphatidylcholine, AAPH, iron sulfate, and hydrogen peroxide were purchased from Sigma (USA). All of the other chemicals were of the highest grade available and the buffers were prepared with a Milli-Q water system (Millipore, Germany).

\section{Purification of 4-NC}

$P$. umbellata roots were purchased from a herbarium supply company (Flora Medicinal, Vale do Ribeira, SP, Brazil). The certified roots $(1 \mathrm{~kg})$ were dried, milled, and exhaustively extracted by ultrasonication for $1 \mathrm{~h}$ with dichloromethane, yielding a crude extract $(184.2 \mathrm{~g})$ after solvent evaporation. The crude extract was initially chromatographed [thin-layer chromatography (TLC); $\mathrm{SiO}_{2}$; dichloromethane:acetone, 99:1 (v/v)] in parallel with previous authentic $P$. umbellata extracts showing a characteristic composition profile. Next, it was chromatographed on a flash-filtering silica gel 60 (0.063-0.2 mm, Merck, USA) column $(90 \times 330 \mathrm{~mm})$ and eluted with a hexane:ethyl acetate gradient elution. The apolar fractions that were obtained were recombined and submitted to a flash chromatography silica gel (0.063-0.2 mm, Merck) column $(90 \times 330 \mathrm{~mm})$ on a Büchi Sepacore prep-MPLC System (Büchi Labortechnik, Switzerland). The sample constituents were eluted with dichloromethane:cyclohexane:methanol $(5: 2: 1, v / v / v)$ on a Sephadex LH-20 (GE Healthcare BioSciences, Japan) column $(49 \times 920 \mathrm{~mm})$ at a flow rate of $40.0 \mathrm{~mL} / \mathrm{min}$ and monitored at 220/280 nm (Büchi UV detector model C-660). Fractions containing 4-NC were detected by TLC analysis and further purified on a Sephadex LH-20 GE column $(49 \times 920 \mathrm{~mm} ; 220 \mathrm{~nm})$ to yield a pale yellow oil $(1.2 \mathrm{~g})$ that was chemically identified as 4-NC by $\left[{ }^{1} \mathrm{H}\right]-$ and $\left[{ }^{13} \mathrm{C}\right]-N M R$. Sample purity was assessed with a peak purity analysis using high-performance liquid chromatography with a photodiode array detector. The chromatographic conditions were as follows: RP-C18 Phenomenex column $(150 \times 4.6 \mathrm{~mm} ; 4 \mu \mathrm{m})$ using ACN:MeOH: $\mathrm{H}_{2} \mathrm{O}(54: 20: 26, \mathrm{v} / \mathrm{v} / \mathrm{v})$ as the mobile phase and a flow rate of $1.0 \mathrm{~mL} / \mathrm{min}$. The peak similarity at three peak spectra (upslope, downslope, and apex) gave values greater than or equal to 0.99 .

\section{DPPH assay}

The free radical-scavenging activity of 4-NC was determined by its ability to reduce the free-radical DPPH following the method of Brand-Williams et al. (20). Small aliquots of ethanol solutions of 4-NC, $\alpha$-tocopherol, or (+)-catechin were added to $75 \mu \mathrm{M}$ DPPH in methanol. These solutions were prepared daily. The total stoichiometric value of $n$ (the number of DPPH that each antioxidant molecule is able to reduce) for each antioxidant was calculated from the absorbance decay measurements at $515 \mathrm{~nm}$ after a 30-min incubation with the various solutions.

\section{Preparation of liposomes}

Egg PC was dissolved in a chloroform:methanol mixture $(2: 1, v / v)$. A lipid film was formed in a glass tube by evaporating the solvent with a nitrogen gas flux. The film was then kept under vacuum overnight to remove any residual organic solvent. To obtain uniform unilamellar vesicles, the lipid film was hydrated with an appropriate volume of Tris- $\mathrm{HCl}$ buffer ( $50 \mathrm{mM}$ Tris, $0.1 \mathrm{mM}$ diethylene triamine pentaacetic acid, $0.05 \mathrm{mM} \mathrm{KCl}, 0.35 \% \mathrm{HCl}$, $\mathrm{pH}$ 7.4) and then extruded through $0.4-\mu \mathrm{M}$ pore size polycarbonate filters using a mini-extruder (Avanti Polar Lipids, Inc., USA). The extrusion process, consisting of 
approximately 21 serial passes, was performed at room temperature (liquid crystalline phase).

\section{Preparation of erythrocyte ghosts}

Human blood, obtained from blood banks (unknown donors), was diluted in phosphate-buffered saline (PBS; $10 \mathrm{mM}$ phosphate, $154 \mathrm{mM} \mathrm{NaCl}, \mathrm{pH} \mathrm{7.4)}$ and centrifuged at $200 \mathrm{~g}$ for $10 \mathrm{~min}$ at $4^{\circ} \mathrm{C}$. The plasma and white blood cells were carefully removed by aspiration after each wash (3 times). For the ghost preparation, the isolated red blood cells (RBCs) were incubated in lysis buffer (5 mM phosphate, $\mathrm{pH} 8.0$ ) overnight. On the next day, the samples were centrifuged at $20,000 \mathrm{~g}$ for $10 \mathrm{~min}$ at $4^{\circ} \mathrm{C}$. To remove hemoglobin, the addition of a lysis buffer and subsequent centrifuging was repeated five times (without incubation). To recover the original shape of the erythrocyte membranes, the sample was centrifuged in PBS twice. At the end of this procedure, concentrated erythrocyte membranes with a whitish color were obtained and stored at $-20^{\circ} \mathrm{C}$ until use.

\section{Incorporation of antioxidants in membranes}

Small aliquots of 4-NC or $\alpha$-tocopherol in ethanol were placed in glass tubes, and the ethanol was evaporated using a nitrogen gas flux. Fifty microliters of egg PC liposomal membranes (initial concentration $16 \mathrm{mM}$ ) or erythrocyte ghost membranes ( $\sim 4 \mathrm{mg}$ protein $/ \mathrm{mL}$ ) was added to the antioxidant film. The membrane suspension was gently agitated and incubated for $1.5 \mathrm{~h}$ at $37^{\circ} \mathrm{C}$ to allow complete incorporation of antioxidants into the membranes. Control measurements were performed before and after this period of incubation. In all of these experiments, concentrations of the antioxidants 4-NC and $\alpha$-tocopherol ranged from 1 to $100 \mu \mathrm{M}$.

\section{Induction of lipid peroxidation}

To induce oxidative stress, the egg PC liposomal membranes that were previously treated with different concentrations of antioxidant molecules (1 to $100 \mu \mathrm{M})$ were added to a solution of $30 \mathrm{mM} \mathrm{AAPH} / \mathrm{Tris}-\mathrm{HCl}$ buffer or to a neutral solution of $0.1 / 1 \mathrm{mM} \mathrm{FeSO} / \mathrm{H}_{2} \mathrm{O}_{2}$ in $50 \mathrm{mM} \mathrm{NaCl}$. The final concentration of egg PC liposomal membranes was $1.6 \mathrm{mM}$ in both experiments. Similarly, erythrocyte ghost membranes with or without antioxidant (1 to $100 \mu \mathrm{M}$ ) were added to a solution of AAPH in PBS or to a neutral solution of $\mathrm{FeSO}_{4}+\mathrm{H}_{2} \mathrm{O}_{2}$ (erythrocyte ghost final concentration of $0.134 \mathrm{mg}$ protein $/ \mathrm{mL}$ ). All of the samples in these four types of experiments were incubated for $3 \mathrm{~h}$ at $37^{\circ} \mathrm{C}$ and were gently agitated every $30 \mathrm{~min}$.

\section{Assessment of antioxidant capacity of 4-NC and $\alpha$-tocopherol}

The formation of thiobarbituric acid-reactive substances (TBARS) was measured according to a previously described protocol (21). After the oxidation process, the suspension of egg PC vesicles or erythrocyte ghost membranes was centrifuged at $20,000 \mathrm{~g}$. Two milliliters of solution containing $15 \%$ trichloroacetic acid, $0.375 \%$ thiobarbituric acid, and $0.25 \mathrm{M} \mathrm{HCl}$ was added to the supernatant of each sample. Subsequently, the samples were heated at $95^{\circ} \mathrm{C}$ in a water bath for approximately $30 \mathrm{~min}$ and rapidly cooled to stop the TBARS reaction. The suspension was centrifuged at $20,000 \mathrm{~g}$ and $25^{\circ} \mathrm{C}$ for $10 \mathrm{~min}$. The supernatant absorbance was read at $532 \mathrm{~nm}$ using a $\mathrm{T} 80+$ spectrophotometer (PG Instruments, England). MDA concentrations were calculated using a molar extinction coefficient of $1.56 \times 10^{5} \cdot \mathrm{M}^{-1} \cdot \mathrm{cm}^{-1}$.

\section{EPR spectroscopy}

After the oxidative stress protocol, erythrocyte ghosts diluted in PBS were centrifuged at $20,000 \mathrm{~g}$ and $4^{\circ} \mathrm{C}$ for 10 min. A small aliquot $(1 \mu \mathrm{L})$ of spin label $5-\mathrm{DSA}$ in ethanol solution $(5 \mathrm{mg} / \mathrm{mL})$ was added to the precipitated membranes $(50 \mu \mathrm{L})$. For EPR measurement, the ghost suspension was transferred to a capillary tube and flamesealed. EPR measurements were performed using a Bruker ESP 300 spectrometer (Bruker, Germany) equipped with an ER 4102 ST resonator at room temperature $\left(24^{\circ}-26^{\circ} \mathrm{C}\right)$. The instrument settings were as follows: microwave power: $2 \mathrm{~mW}$; modulation frequency: $100 \mathrm{kHz}$; modulation amplitude: $1.0 \mathrm{G}$; magnetic field scan: $100 \mathrm{G}$; sweep time: $168 \mathrm{~s}$, and detector time constant: $41 \mathrm{~ms}$. The EPR spectrum simulations were performed using the nonlinear least-squares fitting (NLLS) program developed by Budil et al. (22). In the spectral calculations, the NLLS program includes the magnetic $g$ - and $A$-tensors and the rotational diffusion tensor $(R)$, which are expressed in a system of Cartesian axes fixed in the spin-labeled molecule. To reduce the number of parameters in the fittings and to simplify the simulation, the average rotational diffusion rate, $R_{\mathrm{bar}}$, was calculated by the fitting program using the relation $R_{\mathrm{bar}}=\left(R_{\mathrm{per}}^{2} R_{\mathrm{par}}\right)^{1 / 3}$, where $R_{\text {per }}$ is the perpendicular and $R_{\text {par }}$ is the parallel component of the rotational diffusion (22). $R_{\mathrm{bar}}$ was converted to the parameter rotational correlation time, $\tau_{\mathrm{c}}$, following the relationship $\tau_{\mathrm{c}}=1 / 6 R_{\mathrm{bar}}$. In this study, the spectra were simulated with a model of a single spectral component. Similar to previous studies $(23,24)$, the magnetic parameters were determined based on a global analysis of the overall spectra obtained in this study, and all of the EPR spectra were simulated using the same predetermined parameters. The input parameters of tensors $A$ and $g$ were $A_{x x}: 7.0 \mathrm{G} ; A_{y y}: 7.2 \mathrm{G} ; A_{z z}: 31.0 \mathrm{G}$; $g_{x x}: 2.0083 ; g_{y y}: 2.0060 ; g_{z z}: 2.0027$.

\section{Results}

\section{DPPH radical-scavenging activity}

The H-donating capacity of 4-NC (Figure 1) and $\alpha$-tocopherol was measured for an excess of DPPH radicals. The absorbance decay was more rapid for 4-NC 
and $\alpha$-tocopherol, reaching a stable value of equilibrium after $5 \mathrm{~min}$, compared with $(+)$-catechin, which reached equilibrium after approximately $10 \mathrm{~min}$. 4-NC, which has two available hydroxyl groups, had a stoichiometric value of $n=1.9 \pm 0.4$ (mean $\pm S D$ ), which represents the reduction of almost two DPPH molecules. $\alpha$-tocopherol, which has only one available hydroxyl group, reduced more than one oxidant molecule $(n=1.2 \pm 0.2)$. A previously reported explanation for this finding is that the $\alpha$-tocopherol radical may undergo dimerization, and the newly formed molecule might then be able to reduce a second DPPH molecule (20). For comparison, we also measured the extensively studied scavenger (+)-catechin, which, due to its five available hydroxyl groups, showed the highest DPPH scavenging activity $(n=4.3 \pm 1.4)$.

\section{Antioxidant activity of 4-NC assessed by the TBARS assay}

The protective effect of 4-NC and $\alpha$-tocopherol on oxidative stress in egg $\mathrm{PC}$ vesicles and erythrocyte ghost membranes initiated by AAPH or $\mathrm{FeSO}_{4}+\mathrm{H}_{2} \mathrm{O}_{2}$ was evaluated using the TBARS assay. MDA production as a function of 4-NC concentration is shown in Figure 2 for egg $P C$ vesicles and in Figure 3 for erythrocyte membranes. In egg PC vesicles, the amount of MDA formed with $\mathrm{Fe}(\mathrm{II}) / \mathrm{H}_{2} \mathrm{O}_{2}$ was twice that formed with $\mathrm{AAPH}$. For both oxidants, the level of MDA decreased gradually with the concentration of 4-NC. $\alpha$-tocopherol showed a small protective effect against oxidation by AAPH, and, in the case of $\mathrm{Fe}(\mathrm{II}) / \mathrm{H}_{2} \mathrm{O}_{2}, \alpha$-tocopherol was a pro-oxidant (Figure 2). In erythrocyte ghost membranes, the level of MDA formed with $\mathrm{Fe}(\mathrm{II}) / \mathrm{H}_{2} \mathrm{O}_{2}$ in the absence of an antioxidant was nearly triple that formed with $\mathrm{AAPH}$ (Figure 3). When lipoperoxidation was initiated by AAPH,
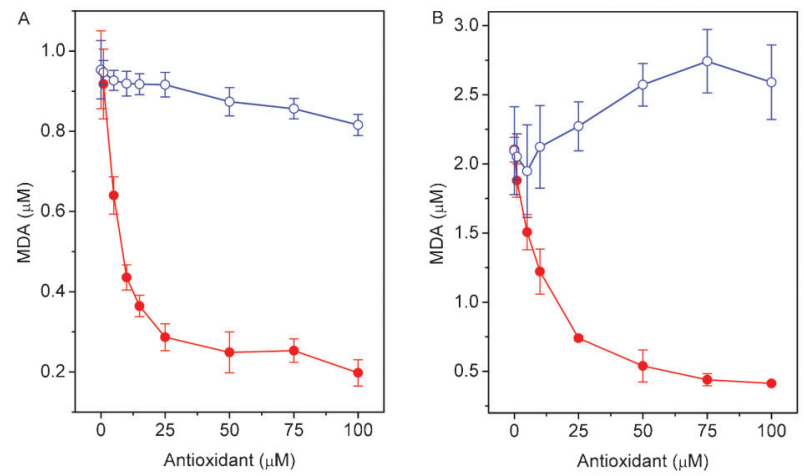

Figure 2. Effect of 4-NC (filled circles) and $\alpha$-tocopherol (open circles) on MDA production in egg PC vesicles oxidized with AAPH $(A)$ or $\mathrm{FeSO}_{4}+\mathrm{H}_{2} \mathrm{O}_{2}(B)$. Egg PC vesicles $(1.6 \mathrm{mM})$ were incubated with several concentrations of $4-\mathrm{NC}$ for $1.5 \mathrm{~h}$ at $37^{\circ} \mathrm{C}$. Lipid peroxidation was initiated by a 3-h incubation with $30 \mathrm{mM} \mathrm{AAPH}$ at $37^{\circ} \mathrm{C}$ or a 1-h incubation with $0.1 / 1 \mathrm{mM} \mathrm{FeSO}_{4} / \mathrm{H}_{2} \mathrm{O}_{2}$ at $37^{\circ} \mathrm{C}$. 4-NC: 4-nerolidylcatechol; MDA: malondialdehyde; $\mathrm{AAPH}$ : 2,2'-azobis(2-aminopropane) hydrochloride; PC: phosphatidylcholine. the level of MDA decreased slowly with increasing antioxidant concentrations (Figure $3 \mathrm{~A}$ ), and protection of $\alpha$-tocopherol against lipoperoxidation was less efficient than the protection of $4-\mathrm{NC}$.

For membranes oxidized by $\mathrm{Fe}(\mathrm{II}) / \mathrm{H}_{2} \mathrm{O}_{2}$ (Figure 3B), MDA formation decreased abruptly with increasing concentration of both antioxidants. These results show that, in ghost membranes, 4-NC had a greater protective effect against attack by aqueous hydroxyl radicals, which are generated by the Fenton reaction, than against attack by peroxyl radicals, which arise from thermal decomposition of AAPH by its reaction with oxygen. At a concentration of $2.5 \mu \mathrm{M} 4-\mathrm{NC}$, the protection rate for hydroxyl radicals was approximately $95 \%$, whereas the same 4-NC concentration showed a maximum protection of approximately $13 \%$ for peroxyl radicals.

\section{Protective effect of 4-NC evaluated by EPR spectroscopy}

EPR spectra of 5-DSA in RBC ghosts, as shown in Figure 4, show a reduction of membrane fluidity upon exposure to $50 \mathrm{mM} \mathrm{AAPH}$ for $3 \mathrm{~h}$ at $37^{\circ} \mathrm{C}$. The change in membrane fluidity was assessed by the spectral EPR parameter $2 \mathrm{~A}_{/ /}$- the outer hyperfine splitting. This is a practice parameter that is measured directly in EPR spectra and has been widely used to monitor membrane fluidity, although, in principle, it is a static parameter associated with orientation distribution of spin labels in the membrane. Another EPR parameter obtained by spectral simulation, the rotational correlation time, has the advantage of taking into account the spectrum as a whole, and provided essentially the same results. For simplicity, only data obtained by $2 \mathrm{~A}_{/ /}$are presented in this study. Membrane alteration was completely prevented by
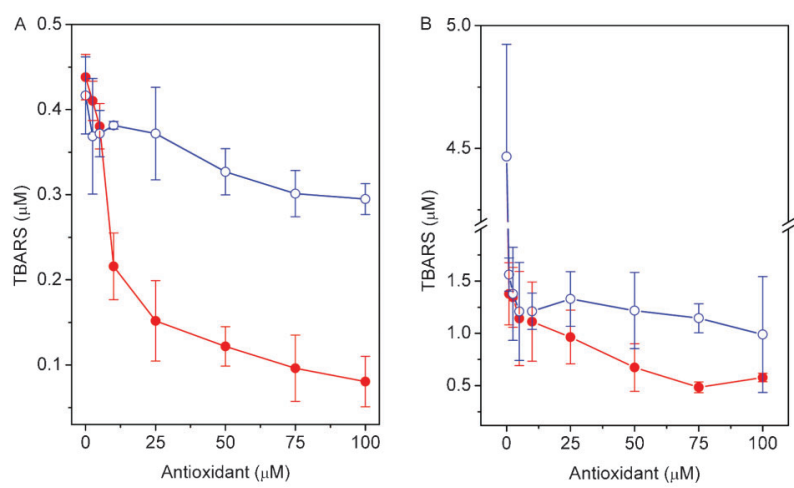

Figure 3. Effect of 4-NC (filled circles) and $\alpha$-tocopherol (open circles) on TBARS formation in erythrocyte ghost membranes oxidized with $\mathrm{AAPH}(A)$ or $\mathrm{FeSO}_{4}+\mathrm{H}_{2} \mathrm{O}_{2}(B)$. Ghosts $(4 \mathrm{mg}$ protein $/ \mathrm{mL}$ ) were incubated with the desired concentrations of 4-NC for $1.5 \mathrm{~h}$ at $37^{\circ} \mathrm{C}$. Erythrocyte ghost membranes were oxidized by incubation with $50 \mathrm{mM} \mathrm{AAPH}\left(3 \mathrm{~h}\right.$ at $\left.37^{\circ} \mathrm{C}\right)$ or $0.2 / 2 \mathrm{mM} \mathrm{FeSO} / \mathrm{H}_{2} \mathrm{O}_{2}\left(1 \mathrm{~h}\right.$ at $\left.37^{\circ} \mathrm{C}\right)$. 4-NC: 4-nerolidylcatechol; TBARS: thiobarbituric acid-reactive substances; AAPH: 2,2'azobis(2-aminopropane) hydrochloride. 


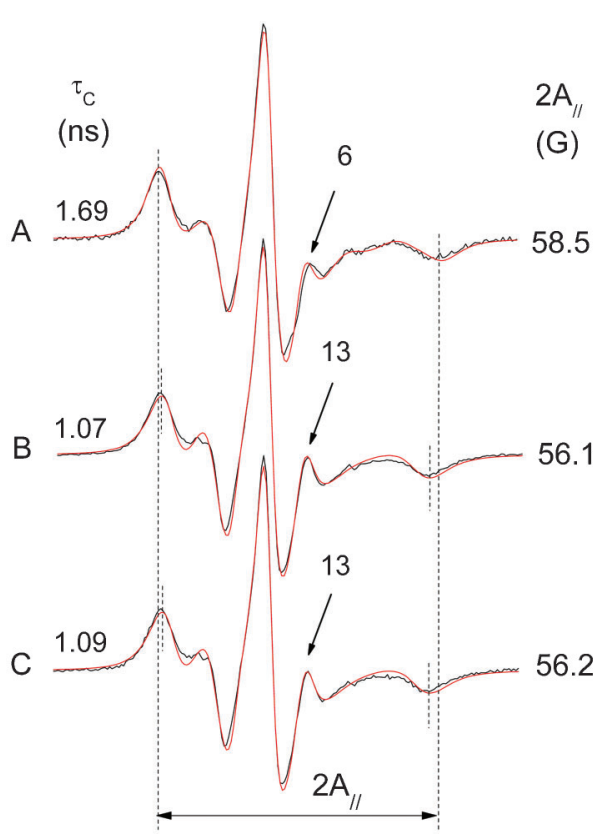

Figure 4. Experimental (black line) and best-fit (red line) EPR spectra of 5-DSA in erythrocyte ghost membranes: $A$, oxidized with $50 \mathrm{mM}$ AAPH; $B$, control sample (not oxidized); $C$, a sample pretreated with $100 \mu \mathrm{M} 4-\mathrm{NC}$ and then oxidized (50 mM AAPH). The EPR parameter $2 A_{/ /}$represents the separation in magnetic-field units between the first and last resonance lines of the spectrum. The vertical lines indicate the $2 A_{/ /}$for the oxidized sample (the total magnetic field scan range of the spectrum was $100 \mathrm{G}$ ). The values of both the $2 A_{/ /}$and the rotational correlation time $\left(\tau_{C}\right)$ parameters (shown in the figure for each spectrum) were greater for the oxidized sample, indicating a reduction in molecular dynamics or increased molecular order. Another indication of this loss of probe mobility in the oxidized sample is the smaller relative intensity of the resonance line, which is indicated by an arrow (and intensity value) in each spectrum. The estimated experimental errors for $2 A_{/ /}$and $\tau_{C}$ are $0.5 \mathrm{G}$ and $0.2 \mathrm{~ns}$, respectively. EPR: electron paramagnetic resonance; AAPH: 2,2'-azobis(2-aminopropane) hydrochloride; 4-NC: 4-nerolidylcatechol.

preincubation with the antioxidant 4-NC for $1.5 \mathrm{~h}$ at $37^{\circ} \mathrm{C}$ (Figure $4 \mathrm{C}$ ). The EPR spectra of 5-DSA in RBC ghosts were not altered in the presence of antioxidants 4-NC or $\alpha$-tocopherol up to a concentration of $100 \mu \mathrm{M}$. A small effect in membrane fluidity was observed for these compounds at concentrations approximately 10 times higher.

The $2 A_{/ /}$value increased with increasing concentrations of AAPH in the RBC ghost suspension and reached a maximum level of approximately $2 \mathrm{G}$ at a concentration of approximately $50 \mathrm{mM}$ AAPH (Figure 5A). Interestingly, the results from the MDA test showed a behavior similar to that of the EPR $2 A_{/ /}$parameter. Based on the plot shown in Figure $5 \mathrm{~A}, 50 \mathrm{mM}$ AAPH was chosen to induce lipoperoxidation in this system. As shown in Figure 5B, preincubation with increasing concentrations of the antioxidant 4-NC completely prevented the change in membrane fluidity due to lipid peroxidation, whereas the
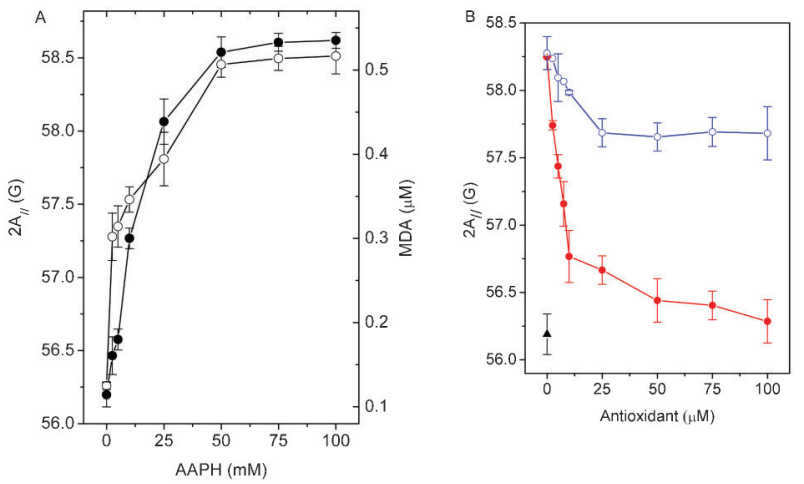

Figure 5. $A$, EPR parameter $2 \mathrm{~A}_{/ /}$of 5-DSA in erythrocyte ghost membranes (filled circles) and MDA formation (open circles) as a function of the concentration of the oxidizing agent AAPH after incubation for $3 \mathrm{~h}$ at $37^{\circ} \mathrm{C}$. B, Antioxidant activity of 4-NC (filled circles) and $\alpha$-tocopherol (open circles), as evaluated by the spectral parameter $2 \mathrm{~A}_{/ /}$. Non-oxidized membranes were used as the control (filled triangle). The erythrocyte membranes were previously incubated with the antioxidants for $1.5 \mathrm{~h}$ at $37^{\circ} \mathrm{C}$ and then incubated with the radical initiator AAPH $(50 \mathrm{mM}$, for $3 \mathrm{~h}$ at $37^{\circ} \mathrm{C}$ ). EPR: electron paramagnetic resonance; 5-DSA: 5-doxyl stearic acid; MDA: malondialdehyde; AAPH: 2,2'-azobis(2aminopropane) hydrochloride; 4-NC: 4-nerolidylcatechol.

corresponding preincubation with $\alpha$-tocopherol provided only partial protection. A decrease of $2 \mathrm{G}$ in the parameter $2 A_{/ /}$relative to the oxidized sample was observed with approximately $50 \mu \mathrm{M}$ 4-NC, whereas the maximum decrease in this spectral parameter for $\alpha$-tocopherol was only $1 \mathrm{G}$.

Figure 6A-C shows the EPR spectra of 5-DSA in RBC ghosts for three samples: oxidized with $200 \mu \mathrm{M} / 2 \mathrm{mM}$ $\mathrm{FeSO}_{4} / \mathrm{H}_{2} \mathrm{O}_{2}$ (spectrum A), preincubated with $100 \mu \mathrm{M}$ 4-NC for $1.5 \mathrm{~h}$ at $37^{\circ} \mathrm{C}$ and then oxidized in the same manner (spectrum B), and a non-oxidized control sample (spectrum C). The EPR parameter $2 A_{/ /}$of 5 -DSA for the oxidized RBC membranes increased by almost $2 \mathrm{G}$ (spectrum A), and $100 \mu \mathrm{M} 4-\mathrm{NC}$ was able to prevent the corresponding reduction of membrane fluidity (spectrum C). The iron concentration dependence of $2 A_{/ /}$for the 5-DSA probe in RBC ghost suspension containing $2 \mathrm{mM}$ $\mathrm{H}_{2} \mathrm{O}_{2}$ is shown in Figure $7 \mathrm{~A}$. The maximum $2 \mathrm{~A}_{/ /}$value observed (approximately $2 \mathrm{G}$ ) is typical for lipoperoxidation (14-16). A concentration of $200 \mu \mathrm{M} / 2 \mathrm{mM} \mathrm{FeSO}_{4} /$ $\mathrm{H}_{2} \mathrm{O}_{2}$ was chosen to examine the antioxidant effects of 4-NC and $\alpha$-tocopherol as a function of their concentration (Figure 7B). In this case, very small concentrations of both antioxidants were sufficient to almost completely prevent the change in membrane fluidity caused by lipid peroxidation.

\section{Discussion}

Several studies have assessed the degree of lipid peroxidation using EPR spectroscopy of spin-labeled 


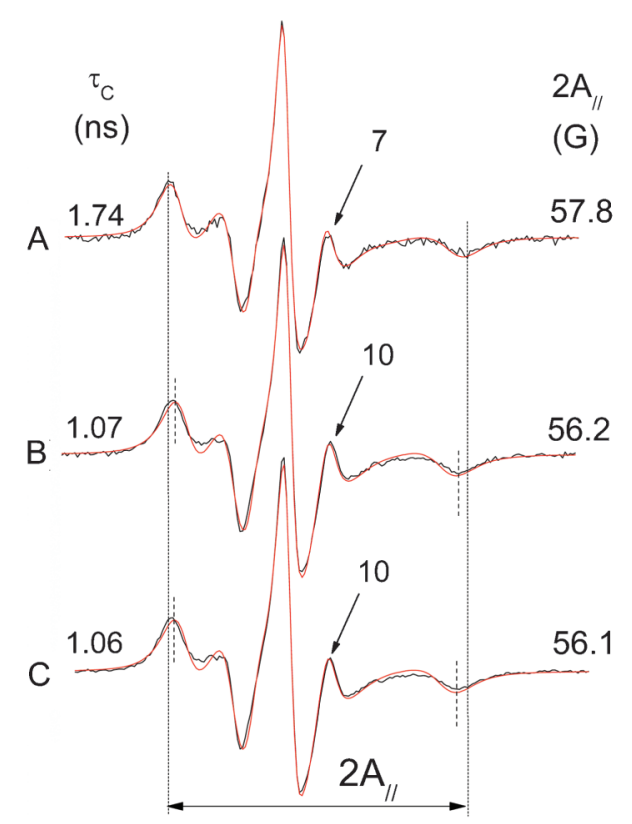

Figure 6. Experimental (black line) and best-fit (red line) EPR spectra of 5-DSA in erythrocyte ghost membranes: $A$, oxidized with $0.2 / 2 \mathrm{mM} \mathrm{FeSO}_{4} / \mathrm{H}_{2} \mathrm{O}_{2} ; B$, pre-treated with $100 \mu \mathrm{M}$ 4-NC and then oxidized; $C$, control sample (non-oxidized). The vertical lines help to visualize the EPR parameter $2 \mathrm{~A}_{/ /}$, the value of which is greater for the oxidized sample, indicating a more rigid membrane. The rotational correlation time $\left(\tau_{\mathrm{C}}\right)$ increased and the relative intensity of the resonance lines, indicated by arrows, decreased with increasing membrane rigidity. EPR: electron paramagnetic resonance; 5-DSA: 5-doxyl stearic acid; 4-NC: 4-nerolidylcatechol.

lipids incorporated into membranes. For instance, the chilling stress in coffee seedlings caused by exposure of the plant to $10^{\circ} \mathrm{C}$ for 6 days in darkness led to membrane stiffness of the plant root, growth inhibition, changes in metabolic rates, and MDA formation. These alterations were interpreted to be a result of lipid peroxidation $(14,16)$. The increase in the $2 A_{/ /}$parameter of 5 -DSA measured directly in intact root-tip segments was approximately $2 \mathrm{G}$ for coffee seedlings exposed to chilling stress. A similar increase in the $2 A_{/ /}$value, generated by ironinduced lipoperoxidation in the mitochondrial membrane, was prevented by $25 \mu \mathrm{M}$ dipyridamole, a coronary vasodilator (15). These data are consistent with the maximum increase in the $2 \mathrm{~A}_{/ /}$parameter of approximately $2 \mathrm{G}$ observed here for ghost membranes oxidized with AAPH or $\mathrm{Fe}(\mathrm{II}) / \mathrm{H}_{2} \mathrm{O}_{2}$. Membrane rigidity in rat liver microsomes, as assessed by fluorescence spectroscopy, has also been associated with lipid peroxidation that is induced by combining $\mathrm{FeCl}_{3}-\mathrm{ADP}-\mathrm{NADPH}$ (19) or $\mathrm{Fe}^{2+}$. ADP-ascorbic acid (18). EPR spectroscopy of the spin label 5-DSA was used to monitor cell membrane fluidity in the human hepatocellular carcinoma cell line HepG2 in a
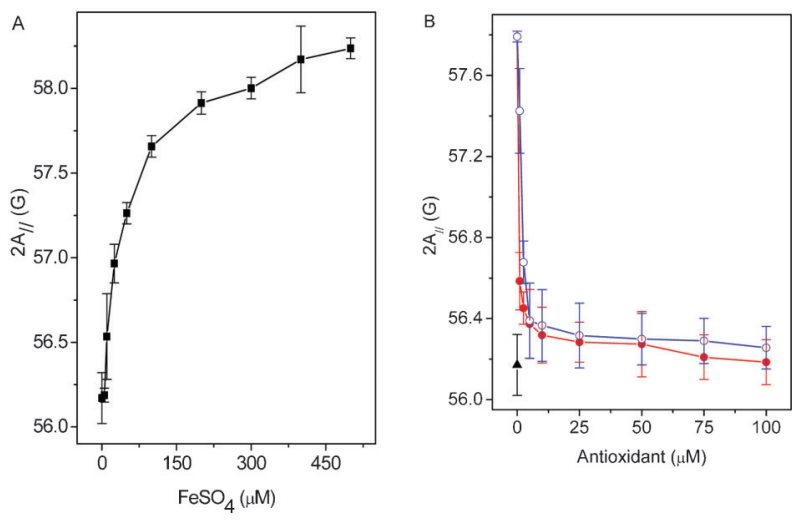

Figure 7. $A, \mathrm{FeSO}_{4}$ concentration dependence of the EPR parameter $2 \mathrm{~A}_{/ /}$of the spin label 5-DSA in erythrocyte ghost membranes. The erythrocyte ghost membranes were incubated with $2 \mathrm{mM} \mathrm{H}_{2} \mathrm{O}_{2}$ and different concentrations of $\mathrm{FeSO}_{4}$ for $3 \mathrm{~h}$ at $37^{\circ} \mathrm{C}$. B, Antioxidant activity of 4-NC (filled circles) and $\alpha$-tocopherol (open circles) as evaluated by the spectral parameter $2 \mathrm{~A}_{/ /}$. Non-oxidized membranes were used as the control (filled triangle). The erythrocyte membranes were previously incubated with antioxidants for $1.5 \mathrm{~h}$ at $37^{\circ} \mathrm{C}$ and then incubated with $0.2 / 2 \mathrm{mM} \mathrm{FeSO}_{4} / \mathrm{H}_{2} \mathrm{O}_{2}$ for $3 \mathrm{~h}$ at $37^{\circ} \mathrm{C}$. EPR: electron paramagnetic resonance; 5-DSA: 5-doxyl stearic acid; 4-NC: 4-nerolidylcatechol.

study that showed that tea catechins can protect cells from lead-induced lipid peroxidation, decreased membrane fluidity, and cell viability (17). In the membrane model of sonicated soybean phospholipid vesicles, the effect of lipid peroxidation with iron/ascorbate on membrane fluidity was dependent on the nitroxide position along the fatty-acid chain. Maximum rigidity was observed for the positional isomers 10- and 12-DSA (25).

The EPR spin-labeling technique is a reliable complementary method to assess the degree of lipid peroxidation in cell membranes. Lipid peroxidation causes a reduction in membrane fluidity, which is well characterized by EPR spectra. Cell membrane fluidity can be modified by the addition of hydrophobic molecules in the millimolar concentration range that are distributed throughout the bilayer. On a time scale of fast rotational motion, these molecules generally destabilize the lipid tail packing and weaken the hydrogen-bonded network of the polar interface. The cases of molecules with opposite effects in the membrane are less common. For example, cholesterol, when added (millimolar range) into the membrane, facilitates lipid packing, generating molecular order or decreased fluidity, which is detectable by the spin label method. In our study systems, the oxidant and the antioxidant compounds were added to the membrane in micromolar concentrations, with the exception of AAPH $(100 \mathrm{mM})$, which is a water-soluble molecule that does not alter membrane fluidity. The present study also suggests that EPR spectroscopy can be useful to assess lipid peroxidation in more complex systems, such as cells, as 
has been performed previously in the root tip segments of coffee seedlings $(14,16)$.

Our results show that in erythrocyte ghost membranes, very small concentrations of $\alpha$-tocopherol or 4-NC were sufficient to prevent the lipid peroxidation caused by hydroxyl radicals, but when the lipid peroxidation was induced by peroxyl radicals, the antioxidants, especially $\alpha$-tocopherol, were much less effective. It has been demonstrated that the hydrophilic radicals generated from AAPH attack the protein component of the RBC membrane, and that $\alpha$-tocopherol can inhibit lipid peroxidation. However, it does not prevent protein oxidation $(26,27)$. Protein degradation could hinder protection against lipid peroxidation for these lipid-soluble antioxidants. However, our results for $\alpha$-tocopherol in egg PC vesicles and ghost membranes were quite different. $\alpha$-tocopherol showed a pro-oxidant effect in egg $\mathrm{PC}$ vesicles when subjected to oxidation by the $\mathrm{Fe}(\mathrm{II}) / \mathrm{H}_{2} \mathrm{O}_{2}$ system (Figure $2 \mathrm{~B}$ ), whereas, for 4-NC, the results for the two membranes were consistent. Yamamoto and Niki (28) have shown that $\alpha$-tocopherol incorporated into soybean vesicles reduces the ferric ion to the more reactive ferrous ion and that $\alpha$-tocopherol may act either as an antioxidant or as a pro-oxidant depending on the experimental conditions. Consistent with our findings, the authors observed that $\alpha$-tocopherol incorporated into intact erythrocyte membranes did not reduce ferric ion in the aqueous phase. Importantly, the erythrocyte membrane is more rigid than the egg PC bilayer, and thus $\alpha$-tocopherol should find greater stability in the erythrocyte membrane, having less ability to fluctuate on the membrane to reach the ferric ions in the aqueous phase.

Interestingly, antioxidants also behave as pro-oxidants under certain conditions, as explained above. Recently, it was demonstrated that 4-NC is a cytotoxic compound with the capacity to induce apoptosis in metastatic melanoma cell lines (8). The main mechanisms of action suggested for this apoptosis-inducing activity were the formation and accumulation of ROS, leading to DNA damage, induction of the tumor suppressor p53, an increase in the pro-apoptotic protein Noxa, and caspase-dependent apoptosis (9). However, we believe that further studies are necessary to demonstrate that the formation of ROS by $4-\mathrm{NC}$ is the cause, rather than a consequence, of induced apoptosis in melanoma cells. $P$. umbellata extracts have also been shown to possess cytotoxic activity, with a high potency for growth inhibition in human cancer cell lines and antitumor activity in Ehrlich ascites carcinoma in male Swiss mice (29).

The physiological function of $\alpha$-tocopherol as an antioxidant has recently been the topic of polemic reviews (30-32). The ability of $\alpha$-tocopherol to act as an antioxidant in vivo has been questioned. In fact, $\alpha$-tocopherol has been shown to function as a cell-signaling agent (30). Other authors argue that as a chain-breaking antioxidant, vitamin $\mathrm{E}$ acts only as the main protector against in vivo lipid peroxidation (31,32). An important feature of $\alpha$-tocopherol is its ability to act as an antioxidant at very low concentrations in biological membranes. Atkinson et al. (32) reviewed the amount of $\alpha$-tocopherol reported for several membranes, as expressed in the molar percentage relative to the amount of phospholipids in each membrane. Measurements of $\alpha$-tocopherol in the membranes of rat liver mitochondria, human platelets, rat lung, rat brain cortex, and rat liver microsomes ranged from 0.1 to $1.0 \mathrm{~mol} \%$. Considering that the phospholipid concentration in RBC membranes is $0.76 \mathrm{mg} / \mathrm{mg}$ protein (33), our data showed that both 4-NC and $\alpha$-tocopherol have a large protective effect at $0.1 \mathrm{~mol} \%$ against $200 \mu \mathrm{M} / 2 \mathrm{mM}$ $\mathrm{FeSO}_{4} / \mathrm{H}_{2} \mathrm{O}_{2}$ (Figure 7B), whereas an appreciable protection from AAPH was observed at $0.4 \mathrm{~mol} \% 4-\mathrm{NC}$, and a moderate level of protection from AAPH was observed at $2.5 \mathrm{~mol} \% \alpha$-tocopherol (Figure 5B). This finding indicates that our in vitro results are consistent with the in vivo data reported for $\alpha$-tocopherol activity in terms of its concentration in the membrane (32).

The irradiation of human skin with solar-simulated ultraviolet light depletes $\alpha$-tocopherol from the stratum corneum, the outermost skin layer (34). At doses below the 0.75 minimal erythema dose, the amount of $\alpha$-tocopherol was depleted by almost $50 \%$ in human stratum corneum and by $85 \%$ in murine stratum corneum (34). These authors (34) suggested that the high susceptibility of $\alpha$-tocopherol to ultraviolet radiation might be partially due to a lack of co-antioxidants in the stratum corneum (35). P. umbellata root extract gel, containing $0.1 \% 4$-NC prevented $\alpha$-tocopherol depletion in the skin of hairless mice following ultraviolet irradiation $(3,4)$. In response to UVB radiation in the skin of hairless mice, MMP-2 and -9 were inhibited in the presence of 4-NC (5). Recently, the single application of a topical $\alpha$-tocopherol-enriched rinse-off product led to significantly increased levels of vitamin $E$ in the stratum corneum, and contributed to the protection of human skin against lipid peroxidation in vivo (36). These findings suggest that 4-NC could be used in topical formulations for treatment of human melanomas or as a topical agent to protect the skin from sunlight irradiation. Due to its hydrophobic nature, 4-NC can be easily incorporated into the intercellular membranes of the stratum corneum and can be associated with fluidity and permeation enhancers such as the monoterpenes 1,8-cineole, limonene, and $\alpha$-terpineol $(23,24)$, which are low in toxicity and could serve as a delivery system for this compound to the epidermis.

Our results show that compound 4-NC, which can be isolated from the native Brazilian species $P$. umbellate, is a potent lipid-soluble in vitro antioxidant. In erythrocyte ghost membranes, both 4-NC and $\alpha$-tocopherol provided very efficient protection against the lipid peroxidation initiated by hydroxyl radicals. However, $\alpha$-tocopherol was less efficient than 4-NC when the lipoperoxidation was initiated by peroxyl radicals. In egg PC vesicles, 4-NC had 
a protective effect against hydroxyl and peroxyl radicals, whereas $\alpha$-tocopherol had a minor protective effect against peroxyl radicals and had a pro-oxidant effect when lipoperoxidation was induced by the free radicals generated by iron/hydrogen peroxide. As a free-radical scavenger, 4-NC displayed a greater ability than $\alpha$ tocopherol to reduce DPPH molecules: 4-NC was able to reduce two free radicals, whereas only one free radical was reduced by $\alpha$-tocopherol.

\section{References}

1. Kijjoa A, Giesbrecht AM, Akissue MK, Gottlieb OR, Gottlieb HE. 4-Nerolidylcatechol from Pothomorphe umbellata. Planta Med 1980; 39: 85-87, doi: 10.1055/s-2008-1074908.

2. Barros SBM, Teixeira DS, Aznar AE, Moreira JA Jr, Ishiiand I, Freitas PCD. Antioxidant activity of ethanolic extracts of Pothomorphe umbellata. Cienc Cult 1996; 48: 114-116.

3. Ropke CD, Meirelles RR, da Silva V, Sawada TC, Barros SB. Pothomorphe umbellata extract prevents alpha-tocopherol depletion after UV-irradiation. Photochem Photobiol 2003; 78: 436-439, doi: 10.1562/00318655(2003)078<0436:PUEPTD > 2.0.CO;2.

4. Ropke CD, Sawada TC, da Silva V, Michalany NS, de Moraes Barros SB. Photoprotective effect of Pothomorphe umbellata root extract against ultraviolet radiation induced chronic skin damage in the hairless mouse. Clin Exp Dermatol 2005; 30: 272-276, doi: 10.1111/j.1365-2230.2005.01749.x.

5. Ropke CD, da Silva V, Kera CZ, Miranda DV, de Almeida $\mathrm{RL}$, Sawada TC, et al. In vitro and in vivo inhibition of skin matrix metalloproteinases by Pothomorphe umbellata root extract. Photochem Photobiol 2006; 82: 439-442, doi: 10.1562/2005-06-29-RA-596.

6. Birkedal-Hansen $\mathrm{H}$. Proteolytic remodeling of extracellular matrix. Curr Opin Cell Biol 1995; 7: 728-735, doi: 10.1016/ 0955-0674(95)80116-2.

7. Inomata S, Matsunaga Y, Amano S, Takada K, Kobayashi $\mathrm{K}$, Tsunenaga $\mathrm{M}$, et al. Possible involvement of gelatinases in basement membrane damage and wrinkle formation in chronically ultraviolet B-exposed hairless mouse. J Invest Dermatol 2003; 120: 128-134, doi: 10.1046/j.15231747.2003.12021.x.

8. Brohem CA, Sawada TC, Massaro RR, Almeida RL, Rivelli DP, Ropke CD, et al. Apoptosis induction by 4nerolidylcatechol in melanoma cell lines. Toxicol In Vitro 2009; 23: 111-119, doi: 10.1016/j.tiv.2008.11.004.

9. Brohem CA, Massaro RR, Tiago M, Marinho CE, Jasiulionis MG, de Almeida RL, et al. Proteasome inhibition and ROS generation by 4 -nerolidylcatechol induces melanoma cell death. Pigment Cell Melanoma Res 2012; 25: 354-369, doi: 10.1111/j.1755-148X.2012.00992.x.

10. Pinto AC, Silva LF, Cavalcanti BC, Melo MR, Chaves FC, Lotufo LV, et al. New antimalarial and cytotoxic 4nerolidylcatechol derivatives. Eur J Med Chem 2009; 44: 2731-2735, doi: 10.1016/j.ejmech.2008.10.025.

11. Rocha E Silva LF, Silva Pinto AC, Pohlit AM, Quignard EL, Vieira PP, Tadei WP, et al. In vivo and in vitro antimalarial activity of 4-nerolidylcatechol. Phytother Res 2011; 25: 1181-1188, doi: 10.1002/ptr.3424.

12. Gutteridge JM. Lipid peroxidation and antioxidants as

\section{Acknowledgments}

The authors are grateful to INGOH, the Goiano Institute of Oncology and Hematology and Hemolabor, and the Clinical Analysis Laboratories for supplying the blood. Research supported by CNPq, CAPES and FAPEG. K.S. Fernandes, S.A. Mendanha and A.H.M. Silva are recipients of fellowships from CAPES. A. Alonso gratefully acknowledges the CNPq for a research grant.

biomarkers of tissue damage. Clin Chem 1995; 41: 18191828.

13. Moon JK, Shibamoto T. Antioxidant assays for plant and food components. J Agric Food Chem 2009; 57: 1655-1666, doi: $10.1021 / \mathrm{jf} 803537 \mathrm{k}$.

14. Alonso A, Queiroz CS, Magalhaes AC. Chilling stress leads to increased cell membrane rigidity in roots of coffee (Coffea arabica L.) seedlings. Biochim Biophys Acta 1997; 1323: 75-84, doi: 10.1016/S0005-2736(96)00177-0.

15. Nepomuceno MF, Alonso A, Pereira-da-Silva L, Tabak M. Inhibitory effect of dipyridamole and its derivatives on lipid peroxidation in mitochondria. Free Radic Biol Med 1997; 23 1046-1054, doi: 10.1016/S0891-5849(97)00135-4.

16. Queiroz CGS, Alonso A, Mares-Guia M, Magalhães AC. Chilling-induced changes in membrane fluidity and antioxidant enzyme activities in Coffea arabica L. roots. Biol Plantarum 1998; 41: 403-413, doi: 10.1023/A:1001802528068.

17. Chen L, Yang $X$, Jiao $H$, Zhao B. Tea catechins protect against lead-induced cytotoxicity, lipid peroxidation, and membrane fluidity in HepG2 cells. Toxicol Sci 2002; 69: 149-156, doi: 10.1093/toxsci/69.1.149.

18. Choe M, Jackson C, Yu BP. Lipid peroxidation contributes to age-related membrane rigidity. Free Radic Biol Med 1995; 18: 977-984, doi: 10.1016/0891-5849(94)00217-8.

19. Garcia JJ, Reiter RJ, Karbownik M, Calvo JR, Ortiz GG, Tan $\mathrm{DX}$, et al. N-acetylserotonin suppresses hepatic microsomal membrane rigidity associated with lipid peroxidation. Eur $\mathrm{J}$ Pharmacol 2001; 428: 169-175, doi: 10.1016/S00142999(01)01342-5.

20. Brand-Williams W, Cuvelier ME, Berset C. Use of a free radical method to evaluate antioxidant activity. LebensmWiss u-Technol 1995; 28: 25-30.

21. Gilbert HS, Stump DD, Roth EF Jr. A method to correct for errors caused by generation of interfering compounds during erythrocyte lipid peroxidation. Anal Biochem 1984; 137: 282-286, doi: 10.1016/0003-2697(84)90086-1.

22. Budil DE, Lee S, Saxena S, Freed JH. Nonlinear-leastsquares analysis of slow-motion EPR spectra in one and two dimensions using a modified Levenberg-Marquardt algorithm. J Magn Reson A 1996; 120: 155-189, doi: 10.1006/jmra.1996.0113.

23. dos Anjos JL, de Sousa ND, Alonso A. Effects of ethanol/lmenthol on the dynamics and partitioning of spin-labeled lipids in the stratum corneum. Eur J Pharm Biopharm 2007; 67: 406-412, doi: 10.1016/j.ejpb.2007.02.004.

24. dos Anjos JL, Alonso A. Terpenes increase the partitioning and molecular dynamics of an amphipathic spin label in stratum corneum membranes. Int J Pharm 2008; 350: 103- 
112, doi: 10.1016/j.ijpharm.2007.08.024

25. Bruch RC, Thayer WS. Differential effect of lipid peroxidation on membrane fluidity as determined by electron spin resonance probes. Biochim Biophys Acta 1983; 733: 216222, doi: 10.1016/0005-2736(83)90525-4.

26. Miki M, Tamai H, Mino M, Yamamoto Y, Niki E. Free-radical chain oxidation of rat red blood cells by molecular oxygen and its inhibition by alpha-tocopherol. Arch Biochem Biophys 1987; 258: 373-380, doi: 10.1016/0003-9861(87)90358-4.

27. Zou CG, Agar NS, Jones GL. Oxidative insult to human red blood cells induced by free radical initiator AAPH and its inhibition by a commercial antioxidant mixture. Life Sci 2001; 69: 75-86, doi: 10.1016/S0024-3205(01)01112-2.

28. Yamamoto K, Niki E. Interaction of alpha-tocopherol with iron: antioxidant and prooxidant effects of alpha-tocopherol in the oxidation of lipids in aqueous dispersions in the presence of iron. Biochim Biophys Acta 1988; 958: 19-23, doi: 10.1016/0005-2760(88)90241-X.

29. Sacoman JL, Monteiro KM, Possenti A, Figueira GM, Foglio MA, Carvalho JE. Cytotoxicity and antitumoral activity of dichloromethane extract and its fractions from Pothomorphe umbellata. Braz J Med Biol Res 2008; 41: 411-415, doi: 10.1590/S0100-879X2008000500010.

30. Azzi A. Molecular mechanism of alpha-tocopherol action. Free Radic Biol Med 2007; 43: 16-21, doi: 10.1016/j. freeradbiomed.2007.03.013.

31. Traber MG, Atkinson J. Vitamin E, antioxidant and nothing more. Free Radic Biol Med 2007; 43: 4-15, doi: 10.1016/ j.freeradbiomed.2007.03.024.

32. Atkinson J, Epand RF, Epand RM. Tocopherols and tocotrienols in membranes: a critical review. Free Radic Biol Med 2008; 44: 739-764, doi: 10.1016/j.freeradbiomed.2007.11.010.

33. Younsi M, Quilliot D, Al-Makdissy N, Delbachian I, Drouin P, Donner M, et al. Erythrocyte membrane phospholipid composition is related to hyperinsulinemia in obese nondiabetic women: effects of weight loss. Metabolism 2002; 51: 1261-1268, doi: 10.1053/meta.2002.35184.

34. Thiele JJ, Traber MG, Packer L. Depletion of human stratum corneum vitamin $\mathrm{E}$ : an early and sensitive in vivo marker of UV induced photo-oxidation. J Invest Dermatol 1998; 110: 756-761, doi: 10.1046/j.1523-1747.1998.00169.x.

35. Packer L. Vitamin E is nature's master antioxidant. Sci Med 1994; 1: 54-63.

36. Ekanayake-Mudiyanselage S, Tavakkol A, Polefka TG, Nabi Z, Elsner P, Thiele JJ. Vitamin E delivery to human skin by a rinse-off product: penetration of alpha-tocopherol versus wash-out effects of skin surface lipids. Skin Pharmacol Physiol 2005; 18: 20-26, doi: 10.1159/ 000081682. 